\title{
Article \\ Genetic Factors of Predisposition and Clinical Characteristics of Rheumatoid Arthritis in Russian Patients
}

\author{
Ekaterina A. Vetchinkina ${ }^{1}\left(\mathbb{D}\right.$, Dmitry S. Mikhaylenko ${ }^{1,2} \mathbb{D}$, Ekaterina B. Kuznetsova ${ }^{1,2}$, Tatiana A. Deryagina ${ }^{2}$, \\ Ekaterina A. Alekseeva ${ }^{1}$, Irina V. Bure ${ }^{1}$, Andrey A. Zamyatnin, Jr. ${ }^{1,3,4, *(D)}$ and Marina V. Nemtsova ${ }^{1,2}$ \\ 1 Institute of Molecular Medicine, Sechenov First Moscow State Medical University (Sechenov University), \\ 119991 Moscow, Russia; katevetchinkina@ya.ru (E.A.V.); dimserg@mail.ru (D.S.M.); \\ kuznetsova.k@bk.ru (E.B.K.); ekater.alekseeva@gmail.com (E.A.A.); bureira@mail.ru (I.V.B.); \\ nemtsova_m_v@mail.ru (M.V.N.) \\ 2 Research Centre for Medical Genetics, 115522 Moscow, Russia; t.deryagina2018@yandex.ru \\ 3 Belozersky Institute of Physico-Chemical Biology, Lomonosov Moscow State University, \\ 119991 Moscow, Russia \\ 4 Department of Biotechnology, Sirius University of Science and Technology, 1 Olympic Ave, \\ 354340 Sochi, Russia \\ * Correspondence: zamyat@belozersky.msu.ru; Tel.: +7-495-622-9843
}

\section{check for} updates

Citation: Vetchinkina, E.A.; Mikhaylenko, D.S.; Kuznetsova, E.B.; Deryagina, T.A.; Alekseeva, E.A.; Bure, I.V.; Zamyatnin, A.A., Jr.; Nemtsova, M.V. Genetic Factors of Predisposition and Clinical Characteristics of Rheumatoid Arthritis in Russian Patients. J. Pers. Med. 2021, 11, 469. https://doi.org/ 10.3390/jpm11060469

Academic Editor: Roberto Díaz Peña

Received: 24 April 2021

Accepted: 21 May 2021

Published: 25 May 2021

Publisher's Note: MDPI stays neutral with regard to jurisdictional claims in published maps and institutional affiliations.

Copyright: (c) 2021 by the authors. Licensee MDPI, Basel, Switzerland. This article is an open access article distributed under the terms and conditions of the Creative Commons Attribution (CC BY) license (https:/ / creativecommons.org/licenses/by/ $4.0 /)$.

\begin{abstract}
Rheumatoid arthritis (RA) is a multifactorial disease caused by a genetic predisposition and environmental factors. Predisposing alleles of various genes have a relatively small influence on the disease risk when they appear separately, but in combination, they predispose an individual to RA development. We genotyped 125 patients with RA including 60 SNPs and sequenced coding part of six genes by next-generation sequencing (NGS) technology on a target panel (IAD177464_185). According to our data, the alleles HLA-DRB1*04, HLA-DRB1*01, HLA-B*27, PTPN22 (rs2476601), TNF (rs1800629), TPMT (rs2842934), and IL4 (rs2243250), and genotypes HLA-DRB1*04:04, HLADRB1*01:16, PTPN22 (rs2476601), TPMT (rs2842934), were significantly associated with the RA development. Associations with clinical criteria (DAS28-CRP, HAQ-DI, and CDAI) and biochemical factors were investigated. We have shown that the PADI4 genotypes (rs11203367, rs2240340, rs11203366, and rs874881) are significantly associated with the baseline levels of DAS28-CRP, HAQDI, and CDAI; genotypes IL23R (rs7530511) and TNFRSF1A (rs748004, rs2228144) with the level of anti citrullinated peptide antibodies (ACPA); the genotypes DHODH (rs3213422) and MTHFR (rs180113) with the concentration of C-reactive protein (CRP); and the genotypes IL2RA (rs2104286), IRAK3 (rs11541076), and IL4R (rs1801275) with the level of rheumatoid factor (RF). Application of targeted NGS panel contributes to expanded genotyping to identify risk groups among the RA patients.
\end{abstract}

Keywords: rheumatoid arthritis; polymorphism; genetic predisposition; genotyping; NGS

\section{Introduction}

Rheumatoid arthritis (RA) is a chronic systemic inflammatory disease associated with joint damage. RA is caused by autoimmune alterations that lead to erosive and destructive changes in connective tissues. RA is characterized by significant clinical polymorphism, progressive severe course, and serious complications, if not treated properly. According to the $\mathrm{WHO}$, the incidence of the disease is $0.3-1 \%$ [1], with higher prevalence in women than in men by a ratio of $3: 1$, respectively [2].

Clinical and genealogical methods revealed a genetic predisposition to RA, so the disease is considered as multifactorial, arising from the interaction of unfavorable alleles of various genes and negative environmental factors [3]. The combination of several alleles associated with RA together either can result in a more severe course of the disease or become a protective factor. Currently, a contribution of molecular genetic factors to the development of RA is estimated as 50-60\% [4]. Due to the high significance of hereditary 
factors, it remains relevant to create panels of genetic markers that reflect the risk of occurrence and characteristics of RA pathogenesis.

The literature describes more than 100 loci associated with RA, both for the human leukocyte antigens (HLA) and non-HLA genes [5]. HLA is a system of human leukocyte antigens that represents antigens for recognition by $\mathrm{T}$ cells. HLA genes are localized in 6 p21.3, and they include nearly $60 \%$ of polymorphic genetic variants of predisposition to RA. Besides, their associations with various clinical and pharmacogenetic characteristics are also shown [6].

RA is common in all populations and ethnic groups. The genome-wide association study (GWAS) has demonstrated that the genes of predisposition to RA may differ in patients of different ethnic groups $[7,8]$. The genetic factors of RA in the Russian population have not been sufficiently studied. Several studies have been published that consider individual polymorphic variants, as well as data on different Slavic groups $[9,10]$.

The allele (genotype) frequency in gnomAD comprehensively reflects the genetic structure of Caucasian populations in general, as well as that of the countries of Western and Northern Europe and of some countries of Eastern Europe. However, the Eastern European populations living in the countries of the former Soviet Union (Belarus, the European part of Russia, Ukraine, and Moldova) remain insufficiently characterized. The study is also aimed at searching for allelic (genotypic) associations with RA that are specific for the Russian population.

The identification of genetic factors that affect the clinical course before disease manifestation will allow one to propose preventive recommendations, as well as to predict the dynamics of the clinical picture and further conduct effective targeted therapy with novel drugs. Using a targeted NGS panel, we analyzed known loci and candidate genes to reveal associations with the pathogenesis, clinical course, and biochemical characteristics of RA in Russian patients.

\section{Materials and Methods}

\subsection{Ethical Approval and Patients}

The study involved 125 RA patients from European part of Russia, over the age of 18 , with the mean age of 50.4 years. The number of women was significantly higher than men (109 and 16, respectively). The median duration of the disease was 5.91 years. The majority of patients $(90.4 \%)$ had high disease activity according to the DAS28, CDAI, and HAQ-DI scales: 1-low (2.6 < DAS28 < 3.2), 2-medium (DAS28 3.2-5.1), and 3-high (DAS28 > 5.1). The initial mean value of DAS28 was 5.94, CDAI-39.43, and HAQ-DI-1.69. The initial level of C-reactive protein (CRP) was $21.0 \mathrm{mg} / \mathrm{L}$, anti-cyclic citrullinated peptide antibodies (anti-CCP) $-664.35 \mathrm{IU} / \mathrm{mL}$, and rheumatoid factor (RF) - $192.2 \mathrm{IU} / \mathrm{mL}$. The level of anti-CCP $>10 \mathrm{IU} / \mathrm{mL}$ was observed in $80.8 \%$ patients, and the level of RF $\geq 15 \mathrm{IU} / \mathrm{mL}$ in $84.0 \%$ of patients. The data are presented in the Table 1 . The main exclusion criteria were: patients with any other inflammatory or systemic diseases, pregnant or lactating women, and patients treated with drugs that targeting IL6 or IL6R.

The current study was performed on DNA samples from the peripheral blood of Russian patients. All subjects gave their informed consent for participation in the study and publication of the results. The study was conducted in accordance with the Declaration of Helsinki, and the protocol was approved by the Ethics Committee of Sechenov First Moscow State Medical University (Sechenov University), 13 July 2016. 
Table 1. Characteristics of the RA patients.

\begin{tabular}{|c|c|}
\hline Clinical Characteristic & $\mathrm{RA}(\mathrm{N}=125)$ \\
\hline $\begin{array}{l}\text { Age (years) } \\
\text { mean } \pm \text { SD } \\
{[\text { Min, max] }}\end{array}$ & $\begin{array}{c}50.4 \pm 13.14 \\
{[22,82]}\end{array}$ \\
\hline $\begin{array}{l}\text { Gender } \\
\text { Female } \\
\text { Male }\end{array}$ & $\begin{array}{c}109(87.2 \%) \\
16(12.8 \%)\end{array}$ \\
\hline $\begin{array}{l}\text { Weight }(\mathrm{kg}) \\
\text { mean } \pm \mathrm{SD} \\
{[\text { Min, } \max ]}\end{array}$ & $\begin{array}{c}73.63 \pm 16.366 \\
{[41.0,131.0]}\end{array}$ \\
\hline $\begin{array}{c}\text { Disease duration (years) } \\
\text { Min, } \max \end{array}$ & $\begin{array}{c}5.91 \\
{[2.61,11.16]} \\
\end{array}$ \\
\hline $\begin{array}{c}\text { Disease severity } \\
\text { Moderate }(\text { DAS28-CRP }>3.2 \text { to } \leq 5.1) \\
\text { High }(\text { DAS28-CRP }>5.1)\end{array}$ & $\begin{array}{c}10(8.0 \%) \\
113(90.4 \%)\end{array}$ \\
\hline $\begin{array}{l}\text { DAS28-CRP } \\
\text { mean } \pm \text { SD } \\
{[\text { Min, } \max ]}\end{array}$ & $\begin{array}{c}5.94 \pm 0.643 \\
{[4.5,8.1]}\end{array}$ \\
\hline $\begin{array}{c}\text { CDAI } \\
\text { mean } \pm \text { SD } \\
{[\text { Min, } \max ]}\end{array}$ & $\begin{array}{c}39.43 \pm 8.701 \\
{[24.8,69.3]}\end{array}$ \\
\hline $\begin{array}{c}\text { HAQ-DI } \\
\text { mean } \pm \text { SD } \\
{[\text { Min, } \max ]}\end{array}$ & $\begin{array}{c}1.6890 \pm 0.4998 \\
{[0.125,2.875]}\end{array}$ \\
\hline $\begin{array}{l}\mathrm{CRP}(\mathrm{mg} / \mathrm{mL}) \\
\text { mean } \pm \mathrm{SD} \\
{[\mathrm{Min}, \max ]}\end{array}$ & $\begin{array}{c}21.0 \pm 20.83 \\
{[1,120]}\end{array}$ \\
\hline $\begin{array}{l}\text { Anti-CCP }(\mathrm{IU} / \mathrm{mL}) \\
\text { mean } \pm \mathrm{SD} \\
{[\mathrm{Min}, \max ]}\end{array}$ & $\begin{array}{c}664.35 \pm 999.308 \\
{[0.4,6044.8]}\end{array}$ \\
\hline $\begin{array}{l}\mathrm{RF}(\mathrm{IU} / \mathrm{mL}) \\
\text { mean } \pm \mathrm{SD} \\
{[\mathrm{Min}, \max ]}\end{array}$ & $\begin{array}{l}192.2 \pm 240.95 \\
{[7,1540]}\end{array}$ \\
\hline $\begin{array}{c}\text { Anti-CCP }(>10 \mathrm{IU} / \mathrm{mL}) \\
\text { Yes } \\
\text { No }\end{array}$ & $\begin{array}{l}101(80.8 \%) \\
22(17.6 \%)\end{array}$ \\
\hline $\begin{array}{c}\mathrm{RF}(\geq 15 \mathrm{IU} / \mathrm{mL}) \\
\text { Yes } \\
\text { No }\end{array}$ & $\begin{array}{c}105(84.0 \%) \\
20(16.0 \%)\end{array}$ \\
\hline $\begin{array}{l}\text { Basal Anti-CCP and RF } \\
\text { Low } \\
\text { Medium } \\
\text { High }\end{array}$ & $\begin{array}{l}25(20.0 \%) \\
81(64.8 \%) \\
17(13.6 \%)\end{array}$ \\
\hline
\end{tabular}

\subsection{DNA Isolation and Genotyping HLA and Non-HLA Genes}

DNA from peripheral blood leukocytes of patients was extracted using the kit "ExtractDNA Blood and Cells" (Eurogen, Russia).

The HLA system was genotyped using the «HLA-DNA-TEX» reagent kits for typing the DRB1 gene and «HLA-B27» (DNA-Technology, Russia) according to the manufacturer's protocols.

Polymorphic variants localized in non-HLA genes were genotyped using the AmpliSeq panel IAD177464_185 (Thermo Fisher Scientific, Waltham, MA, USA). This multi- 
genic panel includes coding sequences of the IL6, IL6R, TNFRSF1A, CTLA4, IL10, IL23R, PADI4, and partially HLA-DRB1 and HLA-B genes, as well as 60 short genome fragments with polymorphic variants (mainly in the coding regions of genes) associated with the development, activity of clinical manifestations, and effectiveness of treatment of patients with RA according to the literature data. A complete list of the analyzed sequences is available in the [11].

The libraries were prepared using the Ion AmpliSeq Library Kit 2.0 (Thermo Fisher Scientific) according to the manufacturer's protocols. The preparation of 540 chips was carried out at the Ion Chef station, followed by semiconductor sequencing on the IonS5 Systems device (Thermo Fisher Scientific, USA). Genetic variants were annotated with ANNOVAR software. Visual data analysis, manual filtering of sequencing artefacts, and sequence alignment were performed using the integrative genomics viewer (IGV).

\subsection{Statistical Analysis}

Statistical analysis of the frequency distribution of alleles and genotypes of patient groups and controls was performed using MS Excel. For HLA-DRB1 and HLA-B27, a comparison was performed for the HLA allele frequencies in a Russian population, calculated based on the total number of alleles and the number of variant alleles from the allele frequency net database (AFND) [12]. For non-HLA genes, allele and genotype frequencies in RA patients were compared with the population frequencies in the Caucasian population, calculated based on the total number of alleles and the number of variant alleles from the Genome Aggregation Database (gnomAD) [13].

For dichotomous variables, the exact Fisher test or the Mann-Whitney test were used; the Chi-square test or the nonparametric Kruskal-Wallis test were used when comparing categorical indicators of three or more independent samples; for all genotypes, the Chi-square test was used for categorical indicators, and ANOVA and Student's t-test were used for pairwise comparisons. For continuous variables, the Kruskal-Wallis test and the Wilcoxon-Mann-Whitney test were used, respectively. The relative risk of RA development was assessed using odds ratio (OR) with a 95\% confidence interval (CI). Multiple hypotheses were corrected using the Benjamin-Hochberg method (FDR test). Statistical analysis was carried out using the statistical program STATISTICA version 13.5.0. $p$-Values $<0.05$ were considered statistically significant for all comparisons.

\section{Results}

\subsection{Identification of Genetic Factors of Predisposition to RA}

The allele frequency and genotype distribution associated with predisposition to RA were estimated in Russian patient samples and control samples. Statistically significant differences were observed for polymorphic gene loci: TNF [rs1800629]; FCGR2A [rs1801274]; IL4 [rs2243250]; IL17A [rs2275913]; PTPN22 [rs2476601]; TPMT [rs2842934]; BTNL2 [rs3817963]; STAT4 [rs7574865]; HLA-B allele 27; groups of HLA-DRB1 *1 and *4 alleles; and genotypes ${ }^{*} 01: 04,{ }^{*} 01: 16,{ }^{*} 04: 04,{ }^{*} 04: 16$. The results are presented in Table 2.

The highest risk of RA among alleles of the HLA-DRB1 was associated with the allele ${ }^{*} 01 \mathrm{OR}=4.7$ [CI: 3.3-6.8], $p=0.0004$ and ${ }^{*} 04 \mathrm{OR}=3.1$ [CI: 2.3-4.26], $p=0.00001$. Among the genotypes of the HLA-DRB1, the highest risk was shown by the genotype *04:04 OR $=13.4$ [CI: 6.4-27.9], $p=0.00001$ and ${ }^{*} 01: 16$ OR $=8.3$ [CI: 3.53-19.55], $p=0.00001$. Genotype *04:16 had an OR value of 4.3 [CI: 1.6-11.7], $p=0.007$, and in the additive interaction model in combination with the HLA-B ${ }^{*} 27$ allele, OR $=9.6$ [CI: 1.8-51.2], $p=0.012$. Genotype ${ }^{*} 01: 03$ was close to the significance level with OR $=2.7$ [CI: 1.05-7.1], $p=0.05$, but in the additive interaction model in combination with HLA- ${ }^{*} 27$ allele demonstrated a significant association OR $=14.5$ [CI: 2.27-92.6], $p=0.004$. The HLA-B*27 allele is associated with the risk of RA OR $=2.2$ [CI: 1.37-3.7], $p=0.001$. Protective properties that reduce the risk of RA were found for alleles HLA-DRB1: $* 07$ (OR $=0.6$ [CI: 0.4-0.9], $p=0.02),{ }^{*} 08(\mathrm{OR}=\mathrm{N} / \mathrm{A}$, $p=0.0076)$, and ${ }^{*} 13$ (OR $=0.5$ [CI: $\left.\left.0.3-0.89\right], p=0.01\right)$. 
Table 2. Polymorphic gene loci with revealed statistically significant differences in the frequencies of alleles and genotypes of polymorphic variants in the studied sample of RA patients in comparison with the population frequencies.

\begin{tabular}{|c|c|c|c|c|}
\hline \multirow{3}{*}{$\begin{array}{c}\text { Non-HLA } \\
\text { Alleles and Genotypes }\end{array}$} & \multicolumn{2}{|c|}{ Frequency of Alleles and Genotypes } & \multirow{3}{*}{$p$} & \multirow{3}{*}{ OR [CI 95\%] } \\
\hline & \multicolumn{2}{|c|}{ (abs. Value/Frequency) } & & \\
\hline & RA $(n=125)$ & Control (GnomAD) & & \\
\hline \multicolumn{5}{|l|}{ PTPN22 (rs2476601) } \\
\hline Allele C & $192 / 0.77$ & $13661 / 0.89$ & 0.0001 & $0.4[0.3-0.57]$ \\
\hline Allele T & $58 / 0.23$ & $1753 / 0.11$ & & $2.3[1.7-3.2]$ \\
\hline $\mathrm{CC}$ & $80 / 0.64$ & $6058 / 0.79$ & 0.001 & $0.5[0.3-0.7]$ \\
\hline $\mathrm{CT}$ & $32 / 0.26$ & $1545 / 0.20$ & & $1.37[0.9-2]$ \\
\hline TT & $13 / 0.1$ & $104 / 0.013$ & & $8.5[4.6-15.56]$ \\
\hline \multicolumn{5}{|l|}{ FCGR2A (rs1801274) } \\
\hline Allele G & $105 / 0.42$ & $7710 / 0.5$ & 0.011 & $0.72[0.56-0.93]$ \\
\hline Allele A & $145 / 0.58$ & $7668 / 0.5$ & & $1.4[1.08-1.8]$ \\
\hline GG & $19 / 0.15$ & $1959 / 0.255$ & 0.025 & $0.52[0.32-0.86]$ \\
\hline GA & $67 / 0.54$ & $3792 / 0.493$ & & $1.2[0.83-1.7]$ \\
\hline AA & $39 / 0.31$ & $1938 / 0.252$ & & $1.3[0.92-1.97]$ \\
\hline STAT4 (rs7574865) & & & 0.025 & \\
\hline Allele G & $181 / 0.72$ & $12071 / 0.78$ & & $0.72[0.55-0.96]$ \\
\hline \multirow[t]{2}{*}{ Allele T } & $69 / 0.28$ & $3331 / 0.22$ & & $1.4[1.04-1.83]$ \\
\hline & & & 0.068 & \\
\hline GG & $64 / 0.52$ & $4717 / 0.62$ & & $0.66[0.5-0.94]$ \\
\hline GT & $53 / 0.42$ & $2637 / 0.34$ & & $1.4[0.99-2]$ \\
\hline $\mathrm{TT}$ & $8 / 0.06$ & $347 / 0.04$ & & $1.45[0.7-3]$ \\
\hline IL4 (rs2243250) & & & 0.0025 & \\
\hline Allele T & $63 / 0.25$ & $2705 / 0.18$ & & $1.6[1.2-2.1]$ \\
\hline \multirow[t]{2}{*}{ Allele C } & $187 / 0.75$ & $12699 / 0.82$ & & 0.63 [0.47-0.84] \\
\hline & & & 0.002 & \\
\hline TT & $9 / 0.07$ & $265 / 0.0344$ & & $2.2[1.1-4.3]$ \\
\hline $\mathrm{CT}$ & $45 / 0.36$ & $2175 / 0.2824$ & & 1.43 [0.99-2.07] \\
\hline $\mathrm{CC}$ & $71 / 0.57$ & $5262 / 0.6832$ & & 0.61 [0.43-0.87] \\
\hline IL17A (rs2275913) & & & 0.034 & \\
\hline Allele G & $143 / 0.57$ & $9822 / 0.64$ & & 0.76 [0.59-0.97] \\
\hline \multirow{2}{*}{ Allele A } & $107 / 0.43$ & $5574 / 0.36$ & & $1.32[1.02-1.7]$ \\
\hline & & & 0.015 & \\
\hline GG & $45 / 0.36$ & $3113 / 0.40$ & & $0.83[0.57-1.2]$ \\
\hline GA & $53 / 0.42$ & $3596 / 0.47$ & & 0.84 [0.59-1.2] \\
\hline AA & $27 / 0.22$ & $989 / 0.13$ & & $1.87[1.2-2.88]$ \\
\hline TPMT (rs2842934) & & & 0.002 & \\
\hline Allele A & $175 / 0.7$ & $12074 / 0.78$ & & $0.64[0.5-0.85]$ \\
\hline \multirow[t]{2}{*}{ Allele G } & $75 / 0.3$ & $3330 / 0.22$ & & $1.55[1.2-2]$ \\
\hline & & & 0.0016 & \\
\hline AA & $63 / 0.5$ & $4714 / 0.61$ & & 0.64 [0.45-0.92] \\
\hline AG & $49 / 0.39$ & $2646 / 0.34$ & & $1.23[0.86-1.77]$ \\
\hline GG & $13 / 0.1$ & $342 / 0.04$ & & $2.5[1.4-4.5]$ \\
\hline TNF (rs1800629) & & & 0.0001 & \\
\hline Allele A & $21 / 0.08$ & $2636 / 0.17$ & & $0.4[0.3-0.7]$ \\
\hline \multirow[t]{2}{*}{ Allele G } & $229 / 0.92$ & $12780 / 0.83$ & & $2.25[1.4-3.5]$ \\
\hline & & & $\mathrm{N} / \mathrm{A}$ & \\
\hline AA & $0 / 0$ & $257 / 0.033$ & & $0[0]$ \\
\hline GA & $21 / 0.17$ & $2122 / 0.275$ & & 0.53 [0.33-0.85] \\
\hline GG & $104 / 0.83$ & $5329 / 0.691$ & & $2.2[1.4-3.54]$ \\
\hline BTNL2 (rs3817963) & & & 0.017 & \\
\hline Allele C & $82 / 0.33$ & $4001 / 0.26$ & & $1.4[1.06-1.8]$ \\
\hline \multirow[t]{2}{*}{ Allele T } & $168 / 0.67$ & $11387 / 0.74$ & & $0.72[0.55-0.94]$ \\
\hline & & & 0.015 & \\
\hline $\mathrm{CC}$ & $17 / 0.14$ & $544 / 0.07$ & & $2[1.23-3.5]$ \\
\hline $\mathrm{CT}$ & $48 / 0.38$ & $2913 / 0.38$ & & $1.02[0.7-1.5]$ \\
\hline TT & $60 / 0.48$ & $4237 / 0.55$ & & 0.75 [0.5-1.07] \\
\hline $\begin{array}{l}\text { HLA-alleles and } \\
\text { genotypes }\end{array}$ & RA $(n=114)$ & Control (AFND) & $p$ & OR [CI 95\%] \\
\hline
\end{tabular}


Table 2. Cont.

\begin{tabular}{|c|c|c|c|c|}
\hline Non-HLA & Frequency o & les and Genotypes & \multirow{3}{*}{$p$} & \multirow{3}{*}{ OR [CI 95\%] } \\
\hline \multirow[t]{2}{*}{ Alleles and Genotypes } & \multicolumn{2}{|c|}{ (abs. Value/Frequency) } & & \\
\hline & RA $(n=125)$ & Control (GnomAD) & & \\
\hline \multicolumn{5}{|l|}{ HLA-DRB1 } \\
\hline Allele ${ }^{*} 01$ & $45 / 19.74$ & $474 / 11.85$ & 0.0004 & $4.7[3.3-6.8]$ \\
\hline Allele *04 & $62 / 27.19$ & $427 / 10.675$ & 0.00001 & $3.1[2.3-4.26]$ \\
\hline Allele *07 & $20 / 8.77$ & $562 / 14.05$ & 0.02 & $0.6[0.4-0.9]$ \\
\hline Allele ${ }^{*} 08$ & $0 / 0$ & $139 / 3.475$ & $\mathrm{~N} / \mathrm{A}$ & $\mathrm{N} / \mathrm{A}$ \\
\hline Allele *13 & $18 / 7.89$ & $548 / 13.7$ & 0.01 & $0.5[0.3-0.89]$ \\
\hline$* 01: 03$ & $5 / 4.39$ & $33 / 1.65$ & 0.05 & 2.7 [1.05-7.1] \\
\hline$* 01: 04$ & $7 / 6.14$ & $49 / 2.45$ & 0.017 & $2.6[1.15-5.9]$ \\
\hline *01:16 & $8 / 7.02$ & $18 / 0.9$ & 0.00001 & 8.3 [3.53-19.55] \\
\hline *04:04 & $13 / 11.4$ & $19 / 0.95$ & 0.00001 & $13.4[6.4-27.9]$ \\
\hline$* 04: 16$ & $5 / 4.39$ & $21 / 1.05$ & 0.007 & $4.3[1.6-11.7]$ \\
\hline \multicolumn{5}{|l|}{ HLA-B27 } \\
\hline B27+ & $21 / 17.8$ & $176 / 8.8$ & 0.001 & 2.2 [1.37-3.7] \\
\hline B27- & $97 / 82.2$ & $1824 / 91.2$ & & $0.45[0.27-0.73]$ \\
\hline
\end{tabular}

GnomAD—Genome Aggregation Database; AFND—allele frequency net database; $p$-value-probability of the null hypothesis; OR-odds ratio; $\mathrm{CI}$-confidence interval. $\mathrm{N}$ - the number of patients in the sample. The $p$-value is shown for comparing allele frequencies in the study population with the control using the Chi-square test and the Fisher exact test.

High-risk RA polymorphisms in non-HLA genes are: PTPN22 [rs2476601] allele T $\mathrm{OR}=2.3$ [CI: 1.7-3.2], $p=0.0001 ;$ TNF [rs1800629] allele G OR = 2.25 [CI: 1.4-3.5], $p=0.0001$; TPMT [rs2842934] allele G OR = 1.55 [CI: 1.2-2], $p=0.002 ;$ IL4 [rs2243250] allele T OR = 1.6 [CI: $1.2-2.1], p=0.0025$, etc. The highest OR values among the genotypes of non-HLA genes are shown for the homozygous TT genotype of the PTPN22 gene OR = 8.5 [CI: 4.6-15.56], $p=0.001$ and the GG genotype of TPMT OR $=2.5$ [CI: 1.4-4.5], $p=0.0016$.

Protective properties among alleles of non-HLA genes were revealed for polymorphisms: PTPN22 [rs2476601] allele C OR = 0.4 [CI: 0.3-0.57], $p=0.0001 ;$ TNF [rs1800629] allele A OR $=0.4$ [CI: 0.3-0.7], $p=0.0001 ;$ TPMT [rs2842934] allele A OR $=0.64$ [CI: 0.5-0.85], $p=$ 0.002; and IL4 [rs2243250] allele C OR $=0.63$ [CI: 0.47-0.84], $p=0.0025$. Protective properties among the genotypes of non-HLA genes were revealed for PTPN22 genotype CC OR $=0.5$ [CI: 0.3-0.7], $p=0.001$; TPMT genotype AA OR = 0.64 [CI: 0.45-0.92], $p=0.0016$, etc.

The correction of multiple hypotheses was carried out using the Benjamin-Hochberg method (FDR test); the adjusted $p$-values are presented in Table 3 . After the correction, the HLA-DRB1*04, HLA-DRB1*01, and HLA-B*27 alleles remained significant, as well as PTPN22 [rs2476601], TNF [rs1800629], TPMT [rs2842934], and IL4 [rs2243250] for non-HLA genes.

Table 3. Adjusted values, obtained using the Benjamin-Hochberg method.

\begin{tabular}{cccccc}
\hline Alleles & $p$ & Adj. $\boldsymbol{p}$ & Genotypes & $\boldsymbol{p}$ & Adj. $\boldsymbol{p}$ \\
\hline HLA-DRB1*04 & 0.00001 & 0.0008 & HLA-DRB1*04:04 & 0.00001 & 0.001 \\
PTPN22(rs2476601) & 0.0001 & 0.004 & HLA-DRB1*01:16 & 0.00001 & 0.001 \\
TNF (rs1800629) & 0.0001 & 0.003 & PTPN22(rs2476601) & 0.001 & 0.038 \\
HLA-DRB1*01 & 0.0004 & 0.008 & TPMT (rs2842934) & 0.002 & 0.046 \\
HLA-B27 & 0.001 & 0.015 & B27 + DRB1*01:16 & 0.002 & 0.077 \\
TPMT (rs2842934) & 0.002 & 0.026 & B27 + DRB1*01:03 & 0.004 & 0.115 \\
IL4 (rs2243250) & 0.0025 & 0.028 & HLA-DRB1*04:16 & 0.007 & 0.16 \\
HLA-DRB1*13 & 0.01 & 0.098 & IL4 (rs2243250) & 0.007 & 0.13 \\
FCGR2A (rs1801274) & 0.011 & 0.095 & BTNL2 (rs3817963) & 0.015 & 0.24 \\
BTNL2 (rs3817963) & 0.017 & 0.13 & IL17A (rs2275913) & 0.015 & 0.22 \\
HLA-DRB1*07 & 0.02 & 0.14 & HLA-DRB1*01:04 & 0.017 & 0.22 \\
STAT4 (rs7574865) & 0.025 & 0.16 & FCGR2A (rs1801274) & 0.026 & 0.29 \\
IL17A (rs2275913) & 0.034 & 0.2 & B27 + DRB1*04:16 & 0.012 & 0.23
\end{tabular}

The values of alleles and genotypes that remained valid after the Benjamin-Hochberg correction are indicated in gray. 


\subsection{Genetic Factors Associated with the Clinical Course of the Disease}

Analysis of the SNPs genotype frequencies and the initial clinical characteristics of the patients in our sample revealed associations for a number of genes and loci. However, when adjusting for multiple hypothesis testing, no significant associations were revealed. The table presents the loci and genes with significant associations with the initial clinical and biochemical parameters, but no significant associations were found for the other loci (Supplementary Material Table S1).

The study of correlations of genotype frequencies with clinical characteristics and biochemical parameters of the patients revealed significant associations mainly for nonHLA genes. The HLA-B27 genotypes were significantly associated only with elevated anti-CCP level $(p=0.008)$, while PADI4 [rs11203367, rs2240340, rs11203366, rs874881], AMPD1 [rs17602729], IL23R [rs10889671, rs11465770], IL4R [rs1801275], IL4 [rs2243250], and IL6 [rs2069849] were significantly associated with the severity of the disease (DAS28, CDAI, HAQ-DI). MTHFR [rs180113] and DHODH [rs3213422] were associated with CRP level; IRAK3 [rs11541076], IL2RA [rs2104286], and IL4R [rs1801275] were associated with the rheumatoid factor (RF) level; and IL23R [rs7539625, rs7530511, rs10889671], IL2RB [rs3218253], IL6R [rs 2228144], STAT4 [rs7574865], and TNFRSF1A [rs767455, rs1800693] were associated with anti-CCP level (Table 4).

Table 4. Genes and loci significantly associated with the clinical characteristics of patients in the study population.

\begin{tabular}{|c|c|c|c|}
\hline Gene & rs & $p$-Value & $\begin{array}{c}\text { Associations with } \\
\text { Baseline Value }\end{array}$ \\
\hline $\begin{array}{l}\text { DHODH } \\
\text { MTHFR }\end{array}$ & $\begin{array}{c}\text { rs3213422 } \\
\text { rs180113 }\end{array}$ & $\begin{array}{c}0.041 \\
0.03\end{array}$ & CRP \\
\hline PADI4 & $\begin{array}{l}\text { rs11203367 } \\
\text { rs2240340 } \\
\text { rs11203366 } \\
\text { rs874881 }\end{array}$ & $\begin{array}{c}0.009 \\
0.012 \\
0.007 \\
\\
\\
0.012 \\
0.02 \\
0.014 \\
0.017 \\
0.016 \\
0.003 \\
0.043\end{array}$ & $\begin{array}{c}\text { CDAI } \\
\text { DAS28 } \\
\text { HAQ-DI }\end{array}$ \\
\hline$A M P D 1$ & rs17602729 & 0.037 & HAQ-DI \\
\hline $\begin{array}{l}H L A-B 27 \\
\quad I L 23 R\end{array}$ & $\begin{array}{c}- \\
\text { rs7539625 } \\
\text { rs10889671 } \\
\\
\text { rs7530511 } \\
\text { rs11465770 }\end{array}$ & $\begin{array}{l}0.008 \\
0.014 \\
0.028 \\
0.023 \\
0.005 \\
0.018\end{array}$ & $\begin{array}{c}\text { Anti-CCP } \\
\text { DAS28 } \\
\text { Anti-CCP } \\
\text { HAQ-DI }\end{array}$ \\
\hline $\begin{array}{c}\text { IL } 2 R B \\
\text { IL6R } \\
\text { STAT4 } \\
\text { TNFRSF1A }\end{array}$ & $\begin{array}{c}\text { rs3218253 } \\
\text { rs2228144 } \\
\text { rs7574865 } \\
\text { rs767455 } \\
\text { rs1800693 }\end{array}$ & $\begin{array}{c}0.022 \\
0.043 \\
0.037 \\
0.022 \\
0.01\end{array}$ & Anti-CCP \\
\hline $\begin{array}{c}I L 2 R A \\
I R A K 3 \\
I L 4 R\end{array}$ & $\begin{array}{c}\text { rs2104286 } \\
\text { rs11541076 } \\
\text { rs1801275 }\end{array}$ & $\begin{array}{l}0.042 \\
0.011 \\
0.027 \\
0.002 \\
0.041 \\
0.014 \\
0.015 \\
0.032\end{array}$ & $\begin{array}{c}\text { RF } \\
\\
\text { DAS28 } \\
\text { CDAI } \\
\text { CDAI } \\
\text { DAS28 } \\
\text { CDAI }\end{array}$ \\
\hline
\end{tabular}


To demonstrate polymorphisms associated with several characteristics, Venn diagrams were constructed (Figure 1). Thus, we identified the loci PADI4 [rs11203367, rs2240340, rs11203366], IL4R [rs1801275], and IL4 [rs2243250], which are associated with the severity of clinical manifestations by several clinical criteria.

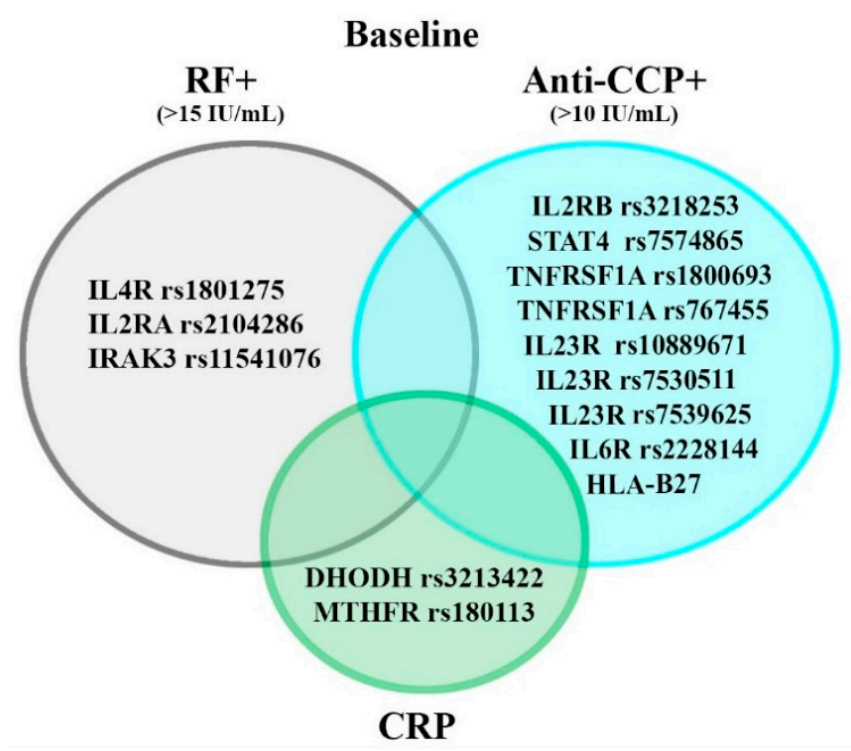

(a)

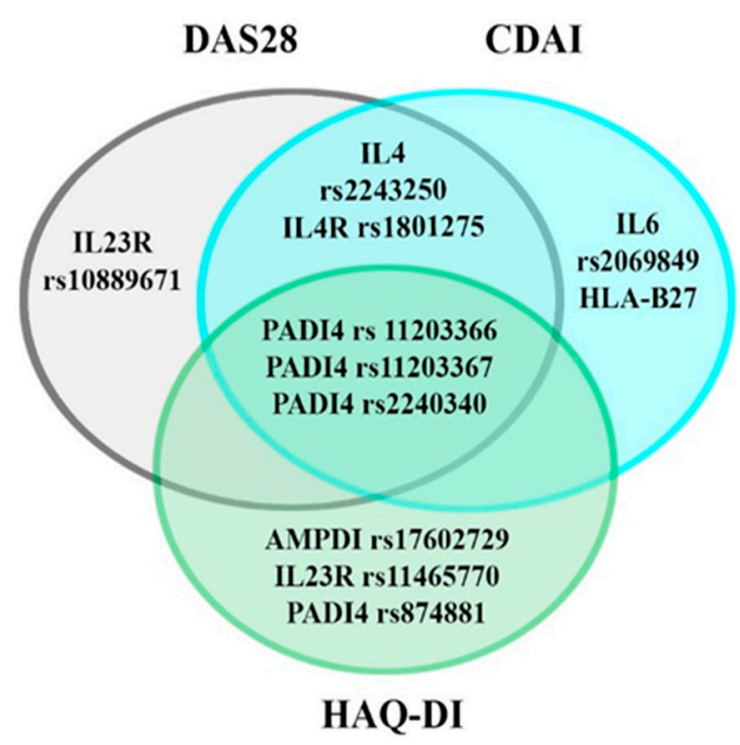

(b)

Figure 1. Venn diagrams, demonstrating the associations of polymorphic variants and biochemical (a) and clinical (b) characteristics of patients.

\section{Discussion}

Predictive medicine, which makes it possible to assess the development and course of the disease, requires the study of not only clinical indices, biochemical parameters, and individual characteristics of patients but also, first of all, the genetic predisposition to its development and the severity of the clinical course. Today, there are many studies investigating the genetic factors of predisposition to RA [3,5,14]. However, their results are obtained in different populations and samples and therefore are ambiguous.

In numerous studies, the carriage of some alleles of the major histocompatibility complex class II HLA-DR1 was significantly associated with the risk of RA. In our study, the HLA-DRB1 ${ }^{*} 01$ and ${ }^{*} 04$ alleles demonstrated predisposition to RA: OR $=4.7$ [CI: 3.3-6.8], $p=0.0004$ and $\mathrm{OR}=3.1$ [CI: 2.3-4.3], $p=0.00001$, respectively. These results are in concordance with those obtained by Guseva I.A. et al. in study conducted in Russian patients. However, only ${ }^{*} 07$ was found in both studies as a protective allele, while other alleles differed, namely, ${ }^{*} 08$ and ${ }^{*} 13$ in our study and ${ }^{*} 02$ and ${ }^{*} 06$ in Guseva's study. Our patients also had the most common genotype *04:04-11.4\%, whereas in the study of Guseva et al.${ }^{*} 01: 01-4.2 \%$ [15]. The variations of the results are probably due to the investigation of early RA, whereas our sample of patients was in the older age group.

Kuranov et al. performed a meta-analysis of the HLA-DRB1 associations with RA development. The risk varied depending on the ethnicity of the population: the highest risk was determined HLA-DRB1*04 among the Western Europe residents for the British $\mathrm{OR}=7.02$, whereas the lowest was in Asians for Pakistanis $\mathrm{OR}=0.65$, with the allele HLA-DRB1*04 being a risk factor for RA, and HLA-DRB1*13 being a protector [16]. HLADRB1*04:01, ${ }^{*} 04: 04$, and ${ }^{*}$ 04:08 are associated with RA in Europeans, and HLA-DRB1*04:05 with RA in Asian populations [17]. In our group, the association of the HLA-DRB1*04 allele and the DRB1*04:04 genotype with the development of RA are in concordance with the abovementioned studies, whereas the data obtained on the HLA-DRB1*01 alleles and the 
HLA-DRB $1^{*} 01^{*} 16$ genotype were different, which could be explained by the population characteristics.

The investigation of Portuguese patients also identified the HLA-DRB1*01 (OR = 1.79) and HLA-DRB1*04 (OR $=2.81)$ polymorphisms as predisposing one to RA, and the HLADRB1*13 allele as protective [18]. The protective effect of the HLA-DRB1 ${ }^{*} 13$ allele $(\mathrm{OR}=0.54$ [CI 0.38-0.77]), as in our study, was shown in a meta-analysis of four European populations. The authors concluded that the frequency of occurrence and negative association of the HLA-DRB1*13 allele varied from north to south, with an increase in OR in the Nordic countries [19].

For non-HLA genes, we found a significant effect of the TT genotype and the PTPN22 $\mathrm{T}$ allele [rs2476601] on the risk of RA development: (TT) OR $=8.5$ [CI: 4.6-15.56], $p=0.001$, (T) $\mathrm{OR}=2.3$ [CI: 1.7-3.2], $p=0.0001$. The PTPN22 encodes lymphoid protein tyrosine phosphatase (LYP), which is a negative regulator of the T-cell receptor-mediated signaling pathway (TCR) and prevents spontaneous activation of $\mathrm{T}$ cells. The non-synonymous substitution of rs2476601 changes arginine (R) at position 620 to tryptophan (W), which affects the physical binding to Csk tyrosine kinase during T-cell activation [20]. The association of PTPN22 polymorphism [rs2476601] with the development of RA was found in different populations. The association of the $\mathrm{T}$ allele with the development of RA has been shown in Europeans and representatives of other races, in the study of a Hungarian sample of patients, as well as in patients of the United Kingdom. The meta-analysis from 2020 reports that PTPN22 [rs2476601] increases the risk of RA in Europeans and Africans [21].

A characteristic of the PTPN22 polymorphism [rs2476601] is the variations of the allele frequencies in different populations. In European populations, there is an increase in the $\mathrm{T}$ allele frequency from south to north. Its frequency in the population of Italy and Sardinia is $2-3 \%$, in the population of Western Europe-7-8\%, and more than $10 \%$ in the population of Scandinavia. Therefore, in some Southern European populations, the association of PTPN22 gene polymorphism with RA is weaker or absent [22]. In Latvian residents, the T allele is associated with the risk of RA development $\mathrm{OR}=1.96$ [CI: 1.5-2.5], $p=0.000006$ and with RF-positive RA: OR $=2.38$ [CI: 1.60-3.54, $p=0.0001$ ] [23]. Song et al. performed a meta-analysis and confirmed that the $\mathrm{T}$ allele is associated with the risk of RA development in different populations [24].

We found a 1.4-fold increase in the risk of RA [CI: 1.04-1.83], $p=0.025$ for the STAT4 polymorphism [rs7574865] in the presence of a minor T allele. It is known that the presence of the T allele increases the expression of STAT4 mRNA and protein, which stimulates and activates cytokine-related signaling pathways [25]. The minor $\mathrm{T}$ allele creates a high risk of developing autoimmune disorders. It is associated with an increase in the level of IFN- $\alpha$, which is indicated for patients with systemic lupus erythematosus (SLE) [26]. A study of RA patients in Slovakia revealed statistically significant associations with RA risk for STAT4 and some other genes (HLA-DRB1*04, PTPN22) [27].

Yongshuai Jiang and co-authors performed a meta-analysis of 125 SNPs related to RA and demonstrated that PTPN22 [rs2476601] and STAT4 [rs7574865] are significantly associated with the RA development, which is in concordance with our results [28]. Fc $\gamma$ receptor 2A (FCGR2A) is expressed in the most types of immunocomponent cells and plays an important role in the regulation of many immunological and inflammatory processes. We found that the FCGR2A [rs1801274] allele T increases the risk of RA in 1.4 times [CI: $1.08-1.8], p=0.011$, and the protective allele $\mathrm{G}$ reduces the risk of RA: OR $=0.72$ [CI: $0.56-0.93], p=0.011$. A meta-analysis performed by Lee et al. revealed an association of the protective allele G of the FCGR2A with RA in Europeans OR = 0.8 [CI: 0.687-0.968], $p=0.02$, but not in Asian population: $\mathrm{OR}=0.9$ [CI: 0.778-1.040] $p=0.15$ [29]. Kyogoku et al. studied the polymorphisms of the FCGR2B, FCGR2A, FCGR3A, and FCGR3B in Japanese population and found no significant association with RA [30]. Due to the small number of studies of the FCGR2A and the small sample sizes, this gene remains insufficiently characterized. 
In our study, we demonstrated that the predisposition to RA in Russian patients is determined mainly by the same genes and polymorphic loci, as in Eastern Europe residents.

Genetic factors can influence not only the risk of development, but also the severity of the clinical course of RA, and therefore serve as diagnostic and prognostic markers. Identification of genetic markers associated with the RA prognosis is often more challenging than identification of predisposition markers. This is because the course and outcome of the disease depends not only on genetic factors but also on epigenetic changes, as well as on individual characteristics of the response to therapy and concomitant diseases.

In the current study, we showed that PADI4 (rs11203367, rs2240340, and rs11203366), IL4R (rs1801275), and IL4 (rs2243250) are associated with the RA clinical characteristics according to the criteria DAS28, CDAI, and HAQ. In some cases, genetic factors that are responsible for the predisposition to RA development are associated with its clinical course.

The PADI4 encodes peptidyl-arginine deaminase, and this enzyme converts arginine amino acid residues to citrulline residues. Deregulation of this process can contribute to citrulline antibodies formation. PADI4 is localized in the region 1p36 and associated with RA development in Asian population. Substitutions in PADI4 in codons G55S [rs11203366], V82A [rs11203367], and G112A [rs874881] reduce the mRNA stability of this gene. According to the meta-analysis, where about 20 thousand RA patients and more than 25 thousand controls were analyzed, polymorphism -94G/A is associated with RA in Asian populations, -92C/G-in African, and -90C/T in Latin American [31].

The carriage of genotypes associated with a decreased activity of PADI4 could be exacerbated by the condition of the patient microbiota or by a previous infectious disease, when the bacteria additionally produce similar targets for citrullination and even have the ability to auto-citrullinate [32]. Deregulation of citrullination contributes to an increase of anti-CCP level and a more severe course of the disease, estimated by the clinical indices. In our study, certain PADI4 genotypes (rs11203367, rs2240340, and rs11203366) were associated with higher baseline values of the clinical indices DAS28, CDAI, and HAQ-DI. Presumably, an analysis of a microbiota condition in patients in combination with genetic factors could be a perspective method for estimation of predisposition to RA.

The IL4 induces the differentiation of naïve T helper cells into Th2 cells and thus affects the development and severity of RA. It fulfils biological activity by binding to the receptor IL4R and stimulating target cell growth by activating transcription and IgE production. Our study revealed that the polymorphic variant of the IL4 [rs2243250] (T allele) is associated with the initial value of the disease activity according to DAS28 ( $p=0.015)$, with the initial value of the clinical CDAI index $(p=0.014)$ and the risk of developing RA: OR = 1.6 [CI: $1.2-2.1], p=0.0025$. Conversely, allele $C$ plays a protective role: $\mathrm{OR}=0.61$ [0.43-0.87], $p=0.0025$. In the study of the Polish population, the distribution of IL4 genotypes in RA patients was similar to that in the control. However, the active form of RA was more often diagnosed in patients with the T allele (CT and TT genotypes) when compared to the homozygous CC genotype. Besides, the disease activity indicators according to DAS28 were significantly increased in T allele carriers [33]. A study in Egypt showed the association of the IL4 polymorphism T allele rs2243250 with RA development (0.03) and the severity of the disease $(<0.001)$, as well as the IL4R polymorphism rs1801275 with RA severity $(<0.001)$ [34]. Carriers of the IL4R allele A1902 rs1801275 were significantly more often RF-positive and had a severe form of RA [35]. SE- and RF-positive African Americans with RA had a higher risk of rheumatoid nodules development in the presence of the AA and AG genotypes of the IL4R polymorphism rs1801275 (OR = 8.45 [CI: 1.57-45.44], $p=0.01$ and OR $=3.57$ [CI: 1.18-10.76], $p=0.02$, respectively) [36]. However, when studying the role of polymorphic variants in the IL4 and IL4R in RA patients of the Caucasian race, no correlation was found with the predisposition to RA and the disease severity [37].

We were unable to identify polymorphic variants that are associated with changes in the overall expression of all three biochemical parameters (RF, anti-CCP, and CRP) that determine the manifestation of a more severe form of seropositive RA. However, we identified loci that were significantly associated with each of these biochemical parameters. 
Rheumatoid factor (RF) is an antibody that recognizes the Fc conservative part of IgM. They are detected in 60-80\% RA patients, and their presence determines the more severe course of the disease and early destructive joints damage [38]. RF is not specific for RA, and occurs in patients with other autoimmune diseases as well [39], whereas anti-CCP are more specific. In the study of Japanese patients, it was shown that the expression of anti-CCP correlates with RF expression. Thus, more than $90 \%$ of patients with anti-CCP-positive RA were also RF-positive [40].

We found a statistically significant association of IL2RA [rs2104286], IRAK3 [rs11541076], and IL4R [rs1801275] with RF-positive RA. Other authors have published data that patients from south-eastern and eastern France have a risk of developing anti-CCP-positive RA in the presence of the HLA-DRB1 ${ }^{*} 04$ and ${ }^{*} 01$ alleles [41]. High RF titers were detected in carriers of the T allele of the IL4 in Egyptian residents, who had a more severe disease in comparison with $\mathrm{C}$ allele carriers [34].

An investigation of $125 \mathrm{RA}$ patients may be not sufficient to identify all the existing differences of the polymorphism frequencies, associated with the clinical course of the disease. Nevertheless, the most pronounced associations with a high probability ratio were identified even in such a limited sample size. It is important for improving the understanding of the genetic predisposition to RA in the Russian population and may encourage further larger-scale studies.

The aim of genetic studies of RA is to predict the predisposition and severity of the disease and find an appropriate treatment for a patient. The genetic heterogeneity of RA can be a serious obstacle in the clinical application of genetic data, and large-scale studies are required to predict the course of the disease and a therapy response. RA patients with genotypes that contribute to the higher RA severity are likely to experience rapid disease progression. Thus, the increased use of therapeutic agents may be more prominent for them. The identification of genetic marker systems that can predict the response to treatment is an important step to the personalized medicine. Application of such systems will help to avoid side effects and decrease costs. However, the application of genetic factors to predict RA severity and a drug response should be developed very carefully, integrating them into a system and considering the ethnic characteristics of the patient sample.

The use of next-generation sequencing will provide a comprehensive approach to genotyping clinical groups of patients with various rheumatic diseases [42]. Using the knowledge of genomics and epigenomics about the mechanisms of disease progression (aberrations in chromatin or DNA methylation, and microRNA pattern) and the influence of environmental factors and microorganisms that promote the cross-reactions with antiCCP and chronic inflammation will explain the resistance of some patients to therapy with certain drugs. The developed targeted NGS panels will allow identification of therapeutic targets and support a personalized approach in medicine to diagnosis and effective RA treatment.

\section{Conclusions}

The obtained data indicate the contribution of the candidate genes identified by us to the RA pathogenesis. We identified polymorphic variants whose alleles and genotypes are associated with gender, age, duration of the disease, baseline levels of CRP, anti-CCP, and RF, as well as the initial clinical characteristics of patients, namely, criteria CDAI, DAS28-CRP, and HAQ-DI. These results will contribute to the identification of RA risk groups among the Russian population and groups of patients with a more severe course of the disease, for which it may be necessary to optimize the monitoring and treatment protocols.

Supplementary Materials: The following are available online at https://www.mdpi.com/article/10 .3390/jpm11060469/s1: Table S1: Statistically significant results of an association analysis between SNPs of non-HLA genes and clinical baseline characteristics of patients. The following are available online at https:/ / doi.org/10.6084/m9.figshare.14454594.v1 (accessed on 21 April 2021) and https: / / doi.org/10.6084/m9.figshare.14199926.v4, IAD177464_185_coverage_summary. 
Author Contributions: All authors participated in the development of the concept and design of the study and have read and agreed to the published version of the manuscript. Design and execution of the research described in the article: I.V.B., E.B.K., E.A.A., and T.A.D.; analysis of the data in the research: E.A.V.; data interpretation: M.V.N., D.S.M.; writing: E.A.V., I.V.B.; critical revisions and editing: M.V.N., A.A.Z.J. All authors have read and agreed to the published version of the manuscript.

Funding: The work was supported by the Ministry of Education and Science of the Russian Federation (Agreement 14.605.21.0003, unique project ID RFMEFI60518X0003).

Institutional Review Board Statement: The study was conducted according to the guidelines of the Declaration of Helsinki, and approved by the Ethics Committee of Sechenov First Moscow State Medical University (Sechenov University), 13 July 2016.

Informed Consent Statement: Informed consent was obtained from all subjects involved in the study.

Data Availability Statement: https://doi.org/10.6084/m9.figshare.14199926.v4 (accessed on 11 March 2021).

Acknowledgments: The authors would like to thank R-Pharm company for access to samples and clinical trial data.

Conflicts of Interest: The authors declare no conflict of interest.

\section{References}

1. WHO. Available online: http://www.who.int/chp/topics/rheumatic/en/ (accessed on 4 December 2012).

2. van Vollenhoven, R.F. Sex Differences in Rheumatoid Arthritis: More than Meets the Eye. BMC Med. 2009, 7, 12. [CrossRef]

3. Deane, K.D.; Demoruelle, M.K.; Kelmenson, L.B.; Kuhn, K.A.; Norris, J.M.; Holers, V.M. Genetic and Environmental Risk Factors for Rheumatoid Arthritis. Best Pract. Res. Clin. Rheumatol. 2017, 3-18. [CrossRef]

4. Karami, J.; Aslani, S.; Jamshidi, A.; Garshasbi, M.; Mahmoudi, M. Genetic Implications in the Pathogenesis of Rheumatoid Arthritis: An Updated Review. Gene 2019, 8-16. [CrossRef]

5. Suzuki, A.; Terao, C.; Yamamoto, K. Linking of Genetic Risk Variants to Disease-Specific Gene Expression via Multi-Omics Studies in Rheumatoid Arthritis. Semin. Arthritis Rheum. 2019, 49, S49-S53. [CrossRef]

6. Mikhaylenko, D.S.; Nemtsova, M.V.; Bure, I.V.; Kuznetsova, E.B.; Alekseeva, E.A.; Tarasov, V.V.; Lukashev, A.N.; Beloukhova, M.I.; Deviatkin, A.A.; Zamyatnin, A.A. Genetic Polymorphisms Associated with Rheumatoid Arthritis Development and Antirheumatic Therapy Response. Int. J. Mol. Sci. 2020, 21, 4911. [CrossRef]

7. Yamamoto, K.; Okada, Y.; Suzuki, A.; Kochi, Y. Genetics of Rheumatoid Arthritis in Asia-Present and Future. Nature Reviews Rheumatology; Nature Publishing Group: Berlin, Germany, 2015; pp. 375-379. [CrossRef]

8. Kuzhir, T. Polygenic basis of the rheumatoid arthritis. Ecol. Genet. 2019, 17, 77-90. [CrossRef]

9. Yatskiu, H.A.; Zlotnikova, M.V.; Sukalo, A.V.; Goncharova, R.I. Characteristic Spectra of Class I and II HLA-Alleles in Patients with Different Clinical Forms of Juvenile Idiopathic Arthritis in the Republic of Belarus. Dokl. Natl. Acad. Sci. Belarus 2020, 64, 209-216. [CrossRef]

10. Bogunia-Kubik, K.; Świerkot, J.; Malak, A.; Wysoczańska, B.; Nowak, B.; Białowąs, K.; Gębura, K.; Korman, L.; Wiland, P. IL-17A, IL-17F and IL-23R Gene Polymorphisms in Polish Patients with Rheumatoid Arthritis. Arch. Immunol. Ther. Exp. (Warsz.) 2015, 63, 215-221. [CrossRef]

11. Mikhaylenko, D.S.; Nemtsova, M.V.; Bure, I.V.; Kuznetsova, E.B.; Alekseeva, E.A.; Deviatkin, A.A.; Zamyatnin, A.A. IAD177464_185_coverage_summary. Csv. Figshare. Dataset. 2021. [CrossRef]

12. AFND. Available online: http:/ / www.allelefrequencies.net/population.asp?pop_id=3322 (accessed on 16 June 2015).

13. gnomAD. Available online: https://gnomad.broadinstitute.org/ (accessed on 17 October 2018).

14. Machaj, F.; Rosik, J.; Szostak, B.; Pawlik, A. The Evolution in Our Understanding of the Genetics of Rheumatoid Arthritis and the Impact on Novel Drug Discovery. Expert Opin. Drug Discov. 2020, 15, 85-99. [CrossRef]

15. Guseva, I.A.; Demidova, N.Y.; Soroka, N.E.; Novikov, A.A.; Lutchihina, E.L.; Alexandrova, E.N.; Lukina, G.V.; Fedorenko, E.V.; Aronova, E.S.; Samarkina, E.Y.; et al. Inununogenetic Aspects of Early Rheumatoid Arthritis. Vestn. Ross. Akad. Meditsinskikh Nauk 2013, 68, 36-43. [CrossRef]

16. Kuranov, A.B.; Boldyreva, M.N.; Momynaliev, K.T. A Meta-Analysis of Associations of HLA-DRB1 with Rheumatoid Arthritis. Immunologiya 2017, 38, 140-143. [CrossRef]

17. Okada, Y.; Kim, K.; Han, B.; Pillai, N.E.; Ong, R.T.H.; Saw, W.Y.; Luo, M.; Jiang, L.; Yin, J.; Bang, S.Y.; et al. Risk for ACPA-Positive Rheumatoid Arthritis is Driven by Shared HLA Amino Acid Polymorphisms in Asian and European Populations. Hum. Mol. Genet. 2014, 23, 6916-6926. [CrossRef]

18. Bettencourt, A.; Carvalho, C.; Leal, B.; Brás, S.; Lopes, D.; Martins Da Silva, A.; Santos, E.; Torres, T.; Almeida, I.; Farinha, F.; et al. The Protective Role of HLA-DRB1*13 in Autoimmune Diseases. J. Immunol. Res. 2015, 2015. [CrossRef] 
19. Van Der Woude, D.; Lie, B.A.; Lundström, E.; Balsa, A.; Feitsma, A.L.; Houwing-Duistermaat, J.J.; Verduijn, W.; Nordang, G.B.N.; Alfredsson, L.; Klareskog, L.; et al. Protection against Anti-Citrullinated Protein Antibody-Positive Rheumatoid Arthritis Is Predominantly Associated with HLA-DRB1*1301: A Meta-Analysis of HLA-DRB1 Associations with Anti-Citrullinated Protein Antibody-Positive and Anti-Citrullinated Protein. Arthritis Rheum. 2010, 62, 1236-1245. [CrossRef]

20. Fiorillo, E.; Orrú, V.; Stanford, S.M.; Liu, Y.; Salek, M.; Rapini, N.; Schenone, A.D.; Saccucci, P.; Delogu, L.G.; Angelini, F.; et al. Autoimmune-Associated PTPN22 R620W Variation Reduces Phosphorylation of Lymphoid Phosphatase on an Inhibitory Tyrosine Residue. J. Biol. Chem. 2010, 285, 26506-26518. [CrossRef]

21. Abbasifard, M.; Imani, D.; Bagheri-Hosseinabadi, Z. PTPN22 Gene Polymorphism and Susceptibility to Rheumatoid Arthritis (RA): Updated Systematic Review and Meta-Analysis. J. Gene Med. 2020. [CrossRef]

22. Gregersen, P.K.; Lee, H.S.; Batliwalla, F.; Begovich, A.B. PTPN22: Setting Thresholds for Autoimmunity. Seminars in Immunology. Semin. Immunol. 2006, 214-223. [CrossRef]

23. Mihailova, A.; Mikazane, H.; Klovins, J.; Nikitina-Zake, L. Association of Protein Tyrosine Phosphatase Non-Receptor 22 (PTPN22) Rs2476601 and Kruppel-like Factor 12 (KLF12) Rs1324913 Single Nucleotide Polymorphisms with Rheumatoid Arthritis in a Latvian Population. Scand. J. Rheumatol. 2011, 491-492. [CrossRef]

24. Song, G.G.; Bae, S.-C.; Kim, J.-H.; Lee, Y.H. The PTPN22 C1858T Polymorphism and Rheumatoid Arthritis: A Meta-Analysis. Rheumatol. Int. 2013, 33, 1991-1999. [CrossRef]

25. Lamana, A.; López-Santalla, M.; Castillo-González, R.; Ortiz, A.M.; Martín, J.; García-Vicuña, R.; González-Álvaro, I. The Minor Allele of Rs7574865 in the STAT4 Gene Is Associated with Increased MRNA and Protein Expression. PLoS ONE 2015, 10, e0142683. [CrossRef]

26. Kariuki, S.N.; Kirou, K.A.; MacDermott, E.J.; Barillas-Arias, L.; Crow, M.K.; Niewold, T.B. Cutting Edge: Autoimmune Disease Risk Variant of STAT4 Confers Increased Sensitivity to IFN- $\alpha$ in Lupus Patients In Vivo. J. Immunol. 2009, 182, 34-38. [CrossRef]

27. Stark, K.; Rovenský, J.; Blažičková, S.; Grosse-Wilde, H.; Ferencik, S.; Hengstenberg, C.; Straub, R.H. Association of Common Polymorphisms in Known Susceptibility Genes with Rheumatoid Arthritis in a Slovak Population Using Osteoarthritis Patients as Controls. Arthritis Res. Ther. 2009, 11. [CrossRef]

28. Jiang, Y.; Zhang, R.; Zheng, J.; Liu, P.; Tang, G.; Lv, H.; Zhang, L.; Shang, Z.; Zhan, Y.; Lv, W.; et al. Meta-Analysis of 125 Rheumatoid Arthritis-Related Single Nucleotide Polymorphisms Studied in the Past Two Decades. PLoS ONE 2012, 7, e51571. [CrossRef]

29. Lee, Y.H.; Bae, S.C. Associations between FCGR2A Rs1801274, FCGR3A Rs396991, FCGR3B NA1/NA2 Polymorphisms and Periodontitis: A Meta-Analysis. Mol. Biol. Rep. 2013, 40, 4985-4993. [CrossRef]

30. Kyogoku, C.; Tsuchiya, N.; Matsuta, K.; Tokunaga, K. Studies on the Association of Fc $\gamma$ Receptor IIA, IIB, IIIA and IIIB Polymorphisms with Rheumatoid Arthritis in the Japanese: Evidence for a Genetic Interaction between HLA-DRB1 and FCGR3A. Genes Immun. 2002, 3, 488-493. [CrossRef]

31. Yang, X.-K.; Liu, J.; Liu, J.; Liang, Y.; Xu, W.-D.; Leng, R.-X.; Pan, H.-F.; Ye, D.-Q. Associations between PADI4 Gene Polymorphisms and Rheumatoid Arthritis: An Updated Meta-Analysis. Arch. Med. Res. 2015, 46, 317-325. [CrossRef]

32. Rashid, T.; Ebringer, A. Autoimmunity in Rheumatic Diseases Is Induced by Microbial Infections via Crossreactivity or Molecular Mimicry. Autoimmune Dis. 2012. [CrossRef]

33. Pawlik, A.; Wrzesniewska, J.; Florczak, M.; Gawronska-Szklarz, B.; Herczynska, M. The -590 IL-4 Promoter Polymorphism in Patients with Rheumatoid Arthritis. Rheumatol. Int. 2005, 26, 48-51. [CrossRef]

34. Mohamed, F.Z.; Mussien, Y.M.; Basiony, E.F. Interleukin-4 (IL-4) and Interleukin-4 Receptor Alpha Chain (IL-4R $\alpha$ ) Gene Polymorphisms in Egyptian Rheumatic Arthritis Patients. Biochem. Lett. 2010, 6, 1-21. [CrossRef]

35. Hussein, Y.; El-Tarhouny, S.; Mohamed, R.; Pasha, H.; Abul-Saoud, A. Association of Interleukin-4 Receptor Gene Polymorphisms with Rheumatoid Arthritis in Egyptian Female Patients. Jt. Bone Spine 2012, 79, 38-42. [CrossRef] [PubMed]

36. Burgos, P.I.; Causey, Z.L.; Tamhane, A.; Kelley, J.M.; Brown, E.E.; Hughes, L.B.; Danila, M.I.; van Everdingen, A.; Conn, D.L.; Jonas, B.L.; et al. Association of IL4R Single-Nucleotide Polymorphisms with Rheumatoid Nodules in African Americans with Rheumatoid Arthritis. Arthritis Res. Ther. 2010, 12, R75. [CrossRef]

37. Marinou, I.; Till, S.H.; Moore, D.J.; Wilson, A.G. Lack of Association or Interactions between the IL-4, IL-4R $\alpha$ and IL-13 Genes, and Rheumatoid Arthritis. Arthritis Res. Ther. 2008, 10, R80. [CrossRef]

38. Nell, V.P.K.; Machold, K.P.; Stamm, T.A.; Eberl, G.; Heinzl, H.; Uffmann, M.; Smolen, J.S.; Steiner, G. Autoantibody Profiling as Early Diagnostic and Prognostic Tool for Rheumatoid Arthritis. Ann. Rheum. Dis. 2005, 64, 1731-1736. [CrossRef]

39. Shmerling, R.H.; Delbanco, T.L. The Rheumatoid Factor: An Analysis of Clinical Utility. Am. J. Med. 1991, 91, 528-534. [CrossRef]

40. Terao, C.; Ohmura, K.; Kochi, Y.; Ikari, K.; Okada, Y.; Shimizu, M.; Nishina, N.; Suzuki, A.; Myouzen, K.; Kawaguchi, T.; et al. Anti-Citrullinated Peptide/Protein Antibody (ACPA)-Negative RA Shares a Large Proportion of Susceptibility Loci with ACPA-Positive RA: A Meta-Analysis of Genome-Wide Association Study in a Japanese Population. Arthritis Res. Ther. 2015, 17. [CrossRef]

41. Balandraud, N.; Picard, C.; Reviron, D.; Landais, C.; Toussirot, E.; Lambert, N.; Telle, E.; Charpin, C.; Wendling, D.; Pardoux, E.; et al. HLA-DRB1 Genotypes and the Risk of Developing Anti Citrullinated Protein Antibody (ACPA) Positive Rheumatoid Arthritis. PLoS ONE 2013, 8, e64108. [CrossRef]

42. Donlin, L.T.; Park, S.H.; Giannopoulou, E.; Ivovic, A.; Park-Min, K.H.; Siegel, R.M.; Ivashkiv, L.B. Insights into Rheumatic Diseases from Next-Generation Sequencing. Nat. Rev. Rheumatol. 2019, 327-339. [CrossRef] 